\title{
PERFIL CLÍNICO DOS MEMBROS DA ASSOCIAÇÃO DOS CELÍACOS DO BRASIL - REGIONAL DE SANTA CATARINA (ACELBRA-SC)
}

\author{
Clarissa Araujo CASSOL, Christine Prim De PELLEGRIN, Mônica Lisboa Chang WAHYS, \\ Maria Marlene de Souza PIRES e Silvia Modesto NASSAR
}

\begin{abstract}
RESUMO - Racional - A doença celíaca é afecção inflamatória do intestino delgado associada à intolerância permanente ao glúten, que ocorre em indivíduos geneticamente susceptíveis. Objetivo - Conhecer as características clínicas e epidemiológicas dessa doença em nosso meio. Método - Tratou-se de estudo descritivo transversal com amostra não-probabilística selecionada entre os membros da Associação dos Celíacos do Brasil - Regional de Santa Catarina, aos quais foi enviado questionário abrangendo diversos aspectos da doença. Resultados - Dos 506 associados, 145 (28,7\%) foram incluídos no estudo - todos celíacos confirmados por biopsia. Suas idades variaram entre 3,3 e 82,5 anos (média de 30,8 anos). A maioria era do sexo feminino (proporção de 2 mulheres para 1 homem). A idade média ao diagnóstico foi de 16 anos para os homens e 26,7 para as mulheres. Os principais sintomas relatados foram distensão abdominal $(71,8 \%)$, dor abdominal (71\%) e diarréia $(65,5 \%)$. No sexo masculino, predominaram diarréia e déficit ponderal enquanto que no sexo feminino aftas, constipação e anemia. Apenas $42,1 \%$ dos associados foram submetidos a biopsia em momento compatível com o diagnóstico correto de doença celíaca (44,2\% relataram biopsia somente em vigência de dieta já isenta de glúten e 11,7\% não souberam informar). Quanto aos testes sorológicos, $61,4 \%$ realizaram pelo menos um teste. Doenças associadas ou complicações foram relatadas por $65,5 \%$; dessas, a mais freqüente foi a intolerância à lactose (33\%). Suplementação vitamínica ou mineral foi indicada em $45 \%$ dos casos e $35,2 \%$ foram submetidos a densitometria óssea. Desses, 59\% relataram um resultado alterado (osteopenia ou osteoporose). Conclus ões - Os resultados apontam para uma tendência de diagnóstico da doença celíaca em idades mais avançadas em nosso meio, especialmente entre as mulheres, e sugerem a necessidade de maiores esclarecimentos do público em geral e da classe médica quanto ao seu correto diagnóstico e tratamento.
\end{abstract}

DESCRITORES - Doença celíaca. Grupo associado. Questionários.

\section{INTRODUÇÃO}

A doença celíaca é uma afecção inflamatória do intestino delgado associada à intolerância permanente ao glúten, que ocorre em indivíduos geneticamente susceptíveis $^{(24)}$.

No passado era tida como rara; entretanto, recentes estudos populacionais têm demonstrado prevalência entre 1/120 e 1/300 na população geral, tanto européia quanto norte-americana ${ }^{(12)}$. No Brasil, estudos recentes entre doadores de sangue demonstraram prevalência de $1 / 681^{(16)}, 1 / 273^{(31)}$ e até $1 / 214^{(35)}$, sugerindo que esta também não é doença rara em nosso país.

Com o objetivo de conhecer melhor as características dessa doença, ainda pouco estudada em nosso meio, desenvolveu-se um projeto de pesquisa visando caracterizar o perfil clínico e epidemiológico dos membros da Associação de Celíacos do Brasil - Regional de Santa Catarina (ACELBRA-SC).

\section{LITERATURA}

A doença celíaca é causada por uma resposta imunológica inapropriada, geneticamente determinada, contra antígenos presentes no glúten do trigo e proteínas similares da cevada e do centeio ${ }^{(33)}$. Afeta, principalmente, as porções proximais do intestino delgado, podendo, nos casos mais graves, estenderse até o íleo e o cólon ${ }^{(10)}$. Os achados anatomopatológicos típicos caracterizam-se por uma mucosa intestinal plana, com vilosidades atrofiadas ou ausentes, hiperplasia de criptas e aumento do número de linfócitos intra-epiteliais ${ }^{(34)}$.

Devido à existência de ampla gama de variações na intensidade, tanto das manifestações clínicas quanto das alterações histopatológicas, em 1997, MÄKI e COLLIN ${ }^{(29)}$ criaram o conceito de iceberg da doença celíaca. Sua teoria explicaria por que elevadas taxas de prevalência estimada com base em testes sorológicos vêm sendo encontradas em populações predominantemente assintomáticas, como doadores de sangue ${ }^{(16)}$.

Universidade Federal de Santa Catarina, Centro de Ciências da Saúde, Departamento de Pediatria. Florianópolis, SC.

Correspondência: Dra. Clarissa Araujo Cassol - Av. Dr. Arnaldo, 455 - sala 1158 - Faculdade de Medicina da USP - Cerqueira César - $01246-903$ - São Paulo, SP. E-mail: clarissa_cassol@terra.com.br 
De acordo com MÄKI e COLLIN(29), o iceberg da doença celíaca conteria em sua base submersa, clinicamente invisível, todos os indivíduos sadios geneticamente susceptíveis à doença — os com haplotipos HLA DQ2 ou DQ8 ${ }^{(25,33)}$. Avançando em direção ao topo do iceberg, encontra-se a chamada doença celíaca latente, característica de indivíduos clinicamente assintomáticos e com arquitetura intestinal normal, em que alterações histológicas de graus variáveis podem ser induzidas por uma dieta rica em glúten ${ }^{(12)}$. Em seguida, ter-se-ía a forma silenciosa da doença, caracterizada pelo achado de alterações histopatológicas típicas em indivíduos clinicamente assintomáticos. Finalmente, no topo do iceberg, seria encontrada a doença celíaca clinicamente sintomática, respondendo por apenas pequena parcela do espectro total da doença ${ }^{(12)}$.

A doença celíaca clinicamente manifesta, por sua vez, pode exibir amplo espectro de apresentações, que foram tradicionalmente divididas entre a forma clássica e a forma não-clássica da doença. A primeira geralmente se manifesta nos primeiros anos de vida com quadro de diarréia crônica, vômitos, irritabilidade, falta de apetite, déficit de crescimento, distensão abdominal, diminuição do tecido celular subcutâneo e atrofia da musculatura glútea ${ }^{(41)}$. Apesar de ter sido considerada, por muito tempo, como exclusiva das crianças, estudos mostram que a doença tem sido cada vez mais diagnosticada em adultos ${ }^{(14)}$, nos quais predomina a forma não-clássica da doença ${ }^{(49)}$. Esta já tem sido, inclusive, considerada a forma de apresentação mais freqüente, segundo alguns autores ${ }^{(49)}$.

A forma não-clássica, ou atípica, caracteriza-se por quadro mono ou paucissintomático, no qual as manifestações digestivas estão ausentes ou, quando presentes, ocupam segundo plano ${ }^{(41)}$. Essa forma, geralmente, se apresenta mais tardiamente na infância ou idade adulta e caracteriza-se por manifestações como: baixa estatura, anemia por deficiência de ferro refratária a ferroterapia oral $^{(20,38)}$, constipação intestinal, hipoplasia do esmalte dentário, osteoporose e esterilidade ${ }^{(41)}$. O espectro de possíveis manifestações atípicas da doença celíaca vem se ampliando constantemente com a descrição de novos achados, como a estomatite aftosa ${ }^{(44)}$ e distúrbios neurológicos e psiquiátricos ${ }^{(5,27)}$.

Além da descrição das numerosas formas atípicas de apresentação da doença, também têm sido descritas várias condições a ela associadas. Essas incluem: a síndrome de Down ${ }^{(48)}$, deficiência seletiva de $\operatorname{IgA}^{(22)}$, diabetes mellitus tipo $\mathrm{I}^{(30)}$, hipotireoidismo ${ }^{(40)}$, intolerância à lactose ${ }^{(47)}$, intolerância à proteína do leite de vaca, dermatite herpetiforme ${ }^{(10)}$, infertilidade ${ }^{(39)}$, abortos de repetição ${ }^{(17)}$, uveíte, osteoporose e osteopenia ${ }^{(23,32)}$, entre outras.

Grande parte dessas descobertas, como já foi dito, foi graças ao desenvolvimento de testes sorológicos sensíveis e específicos, que permitiram o rastreamento da doença celíaca em populações selecionadas. O primeiro desses testes, introduzido no início dos anos 80, consistia na dosagem sérica de imunoglobulinas IgA e IgG contra a gliadina (a fração etanol-solúvel do glúten). Infelizmente, esses testes apresentavam moderada sensibilidade (75\%-90\% para a IgA anti-gliadina e $69 \%-85 \%$ para a IgG) e especificidade $(82 \%-95 \% \text { para a } \operatorname{IgA} \text { e } 73 \%-90 \% \text { para a } \operatorname{IgG})^{(13)}$. Em 1983 , CHORZELSKI et al. ${ }^{(8)}$ detectaram no soro de pacientes com doença celíaca e dermatite herpetiforme um auto-anticorpo dirigido contra a matriz de colágeno de tecidos humanos e de macacos, que foi denominado anti-endomísio. Desde então, sua dosagem tem sido reconhecida como um marcador sensível e específico para a enteropatia sensível ao glúten da doença celíaca e da dermatite herpetiforme, com valores de sensibilidade entre $85 \%$ e $98 \%$ e de especificidade entre $97 \%$ e $100 \%{ }^{(8)}$. Seus valores demonstraram, ainda, estarem relacionados com o grau de atividade da doença, o que os tornou valiosos indicadores de resposta a uma dieta isenta de glúten ${ }^{(8)}$. Recentemente, descobriu-se ser a transglutaminase tecidual o auto-antígeno contra o qual são dirigidos os anticorpos anti-endomísio $^{(26)}$. A partir de então, a detecção de anticorpos anti-transglutaminase tornou-se o mais novo teste sorológico de rastreamento da doença celíaca, com valores de sensibilidade e especificidade entre 90\%-98\% e 97\%-100\%, respectivamente ${ }^{(13)}$.

Ainda que o diagnóstico de doença celíaca possa ser sugerido pelas manifestações clínicas, presença de doenças associadas ou testes sorológicos e laboratoriais, sua confirmação somente se dará pela demonstração das alterações histopatológicas típicas em biopsias do intestino delgado, que permanecem como o padrãoouro para o diagnóstico ${ }^{(34)}$. De acordo com os Critérios Revisados para o Diagnóstico da Doença Celíaca, da Sociedade Européia de Gastroenterologia, Hepatologia e Nutrição Pediátrica (ESPGHAN), a obtenção de uma biopsia intestinal anormal na presença de sintomas ou testes sorológicos sugestivos, seguida de resposta clínica ou sorológica favorável na vigência de dieta isenta de glúten é considerada suficiente para confirmar o diagnóstico, desde que outras causas de atrofia vilositária sejam excluídas ${ }^{(13)}$. Nos casos em que o diagnóstico é duvidoso, recomenda-se que, após um período de restrição de glúten, este seja reintroduzido na dieta, a fim de observar o surgimento de alterações clínicas, sorológicas ou histológicas típicas que confirmem o diagnóstico ou o afastem definitivamente ${ }^{(13)}$.

Tantos cuidados no estabelecimento do diagnóstico de doença celíaca são importantes porque, uma vez estabelecido, este implicará na adoção de dieta totalmente isenta de glúten de forma definitiva e permanente. A não-aderência à dieta, mesmo que não leve ao surgimento de sintomas, implica no risco de complicações a longo prazo, como o linfoma intestinal não$\operatorname{Hodgkin}^{(6)}$, neoplasias malignas do intestino delgado e do fígado ${ }^{(36)}$, além de deficiências de inúmeras vitaminas e minerais.

O distúrbio metabólico mais freqüente na doença celíaca é a diminuição da massa óssea, pela má absorção de cálcio e vitamina D. Em crianças, isso pode levar ao raquitismo, enquanto em adultos levará a diferentes graus de osteopenia e osteoporose ${ }^{(23,32)}$, aumentando o risco de fraturas, especialmente em idosos ${ }^{(45)}$.

Uma vez que a doença celíaca é afecção relativamente comum e tem potencial para levar a complicações graves, salienta-se a importância de estudos nessa área, especialmente nos países da América, onde a doença era tida como rara. Recentes pesquisas têm revelado o quão subdiagnosticada ainda é em nosso continente, mesmo em países desenvolvidos, como a América do Norte. Antes do surgimento de testes sorológicos de rastreamento, a prevalência estimada da doença celíaca naquele país era de 1:4.600 habitantes; entretanto, com o rastreamento com anticorpos anti-endomísio em doadores de sangue, descobriu-se que esta prevalência pode ser muito maior - de 1:250 a 1:300 habitantes ${ }^{(18)}$. Esses dados levam a concluir que grande número de celíacos, atualmente, ainda permanece sem diagnóstico, o que provavelmente decorra tanto do alto índice de apresentações atípicas, quanto do baixo índice de suspeita por 
parte dos médicos. Dessa forma, reforça-se a importância de se conhecerem as características específicas de apresentação dessa doença em nosso meio, pois somente através da identificação das suas várias formas de apresentação clínica e das potenciais doenças associadas é que se chegará à suspeita do seu diagnóstico.

Como seria muito difícil ter acesso a toda a população de celíacos de determinada área com o intuito de estudá-la, uma estratégia que pode ser utilizada para este fim é a análise de um conjunto de indivíduos já diagnosticados, agrupados em fonte sabidamente conhecida. Amostra relativamente fácil de se acessar são os membros de uma associação de pacientes com a doença. Esse tipo de abordagem foi recentemente utilizado nos Estados Unidos, em estudo de caráter nacional ${ }^{(18)}$ e também no Estado de São Paulo, entre os membros da
Associação de Celíacos do Brasil (ACELBRA) daquele Estado ${ }^{(42,43)}$. No presente estudo, a mesma estratégia foi adotada, com o intuito de determinar o perfil clínico dos membros catarinenses da Associação dos Celíacos do Brasil (ACELBRA-SC).

\section{MÉTODO}

Tratou-se de estudo observacional descritivo transversal, baseado em amostra não-probabilística extraída dos 506 membros da ACELBRA-SC no ano de 2004. Todos os associados foram convidados a participar da pesquisa por meio de carta contendo: 1) folha de apresentação do projeto de pesquisa; 2) questionário abordando diversos aspectos da doença (Figura 1); 3) Termo de

\section{UNIVERSIDADE FEDERAL DE SANTA CATARINA \\ CENTRO DE CIÊNCIAS DA SAÚDE \\ DEPARTAMENTO DE PEDIATRIA \\ PESQUISA: "PERFIL CLÍNICO DOS MEMBROS DA ACELBRA-SC"}

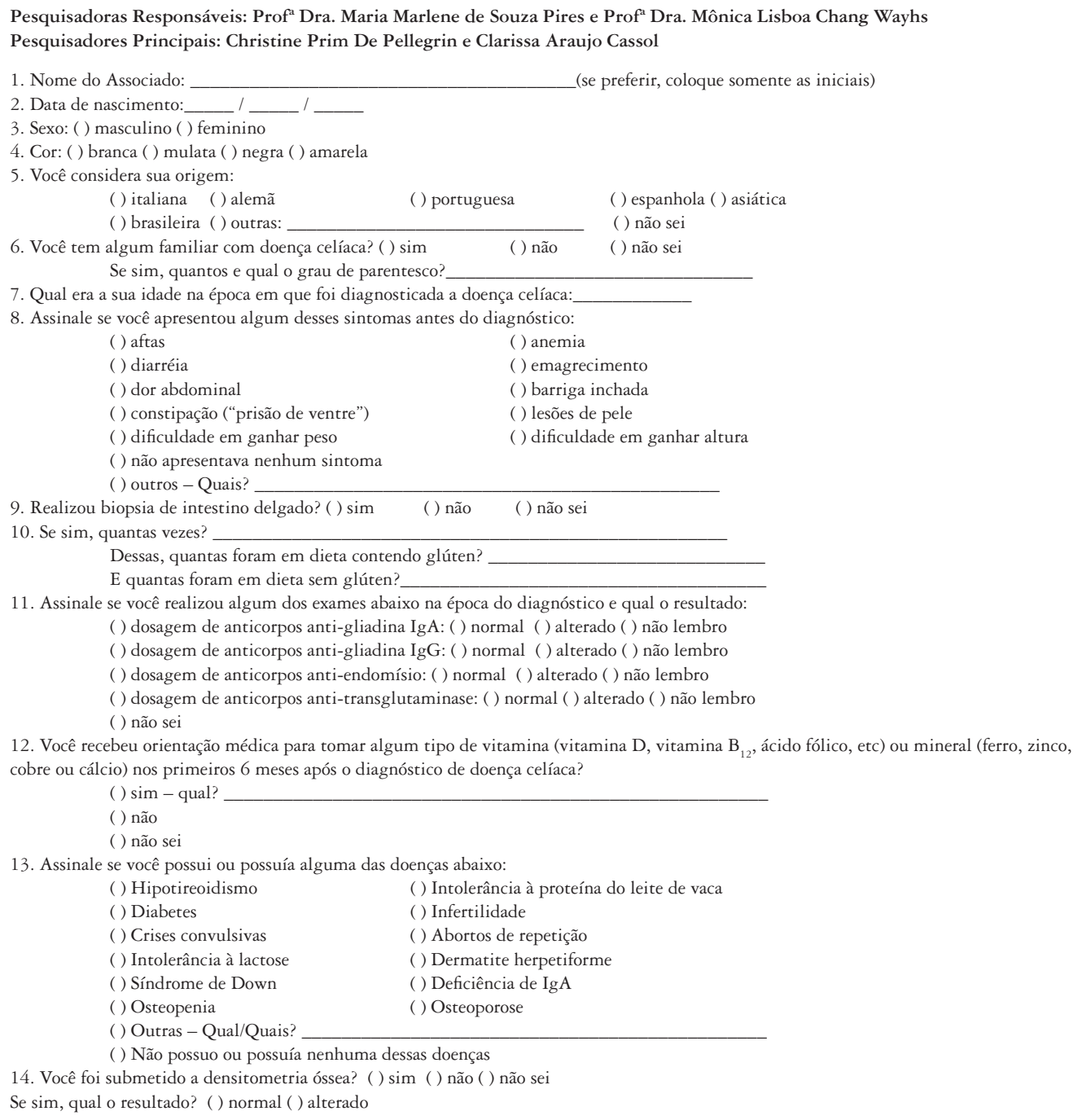

FIGURA 1. Questionário enviado aos membros da ACELBRA-SC 
Consentimento Livre e Esclarecido (TCLE); 4) envelope selado e endereçado para resposta.

O questionário inicialmente elaborado foi submetido a avaliação da diretoria da ACELBRA-SC e, então aplicado, a título de teste, aos membros presentes em uma das reuniões. Após essa avaliação inicial, o questionário definitivo foi elaborado, impresso (Figura 1) e enviado aos associados durante o mês de setembro de 2004.

O projeto foi aprovado pelo Comitê de Ética em Pesquisa com Seres Humanos da Universidade Federal de Santa Catarina.

Foram incluídos no estudo todos os associados que reenviaram o questionário respondido (parcial ou totalmente) e o TCLE devidamente preenchido e assinado dentro do período de 90 dias após a postagem. Foram excluídos aqueles que afirmaram não serem celíacos e os que não possuíam biopsia da segunda porção duodenal, confirmando o diagnóstico da doença.

Os dados coletados foram digitados em planilha do tipo Excel $^{\circledR}$ e analisados com o auxílio do programa Statistica ${ }^{\circledR}$ 6.0.

\section{RESULTADOS}

Das 506 cartas enviadas, $33(6,5 \%)$ retornaram aos pesquisadores devido à mudança ou incompletude do endereço. Retornaram 173 cartas como resposta (34\%), dessas foram excluídas 9 por falta do TCLE, 1 por falta de identificação do remetente e 2 pelo fato de os associados afirmarem não serem celíacos. Das 161 cartas que restaram, $16(10 \%)$ eram de associados que não possuíam biopsia confirmando a doença, tendo sido, por isso, também excluídas. Os resultados que se seguem fazem referência aos 145 membros finalmente incluídos na pesquisa, correspondendo a $28,7 \%$ do total de membros da ACELBRA-SC na ocasião.

Com o objetivo de avaliar a representatividade da amostra em relação ao total de membros da ACELBRA-SC, foi calculada a distribuição por sexo nos dois grupos. Do total de membros da ACELBRA-SC, $65 \%$ eram mulheres e $35 \%$, homens, enquanto nesta amostra, $68 \%$ eram mulheres e $32 \%$, homens; resultando numa relação de 1.8 mulheres para cada homem na ACELBRA$\mathrm{SC}$ e de 2.1 mulheres para cada homem na amostra.

Quanto à cor, $95 \%$ dos participantes se consideraram brancos; $3,5 \%$ pardos, e apenas um $(0,7 \%)$ negro. Em relação à origem, predominou a brasileira (43\%), seguida pela italiana $(29,7 \%)$, alemã $(29 \%)$ e portuguesa $(21,4 \%)$ - a soma desses percentuais ultrapassa $100 \%$ porque foi permitido aos participantes assinalarem mais de uma resposta nessa questão. No geral, $84 \%$ dos participantes consideraram possuir algum grau de ascendência européia.

História familiar positiva para doença celíaca foi relatada por $27 \%$ dos associados.

A média de idade dos participantes foi igual a 30,8 anos, variando entre 3,3 e 82,5 anos. Essa média diferiu significantemente entre os sexos, tendo sido de 35,5 anos para as mulheres e de 22 anos para os homens.

Com relação à idade por ocasião do diagnóstico, esta se concentrou na faixa dos 20 aos 40 anos (Figura 2).

Calculou-se também a distribuição percentual de diagnósticos por faixa etária entre os sexos (Figura 3), que mostrou predomínio masculino nos diagnósticos feitos até os 20 anos de idade, e feminino nos diagnósticos feitos após os 20 anos $\left(X^{2}=14,1948\right.$; graus de liberdade $=4 ; P=0,0067$ ).

A idade média ao diagnóstico também variou entre os sexos, tendo sido de 16 anos para os homens e de 26,7 para as mulheres $(\mathrm{U}=1487,5 ; \mathrm{Z}=3,21 ; P=0,0013)$.

Quanto à sintomatologia prévia ao diagnóstico, os pacientes puderam assinalar mais de um sintoma, tendo sido a distensão abdominal o sintoma mais freqüentemente relatado, seguida de dor abdominal e diarréia (Figura 4).

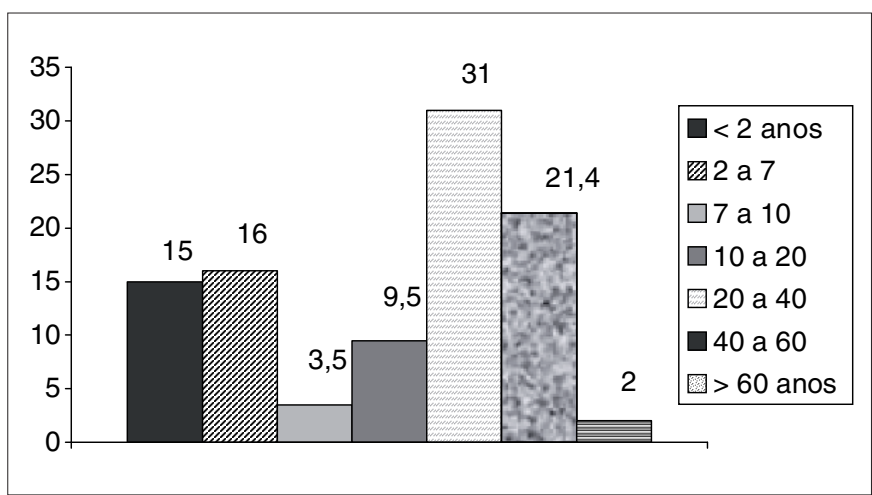

FIGURA 2. Idade ao diagnóstico dos associados da ACELBRA-SC: percentual por faixas etárias $(\mathrm{n}=143)$. Fonte: ACELBRA-SC 2004

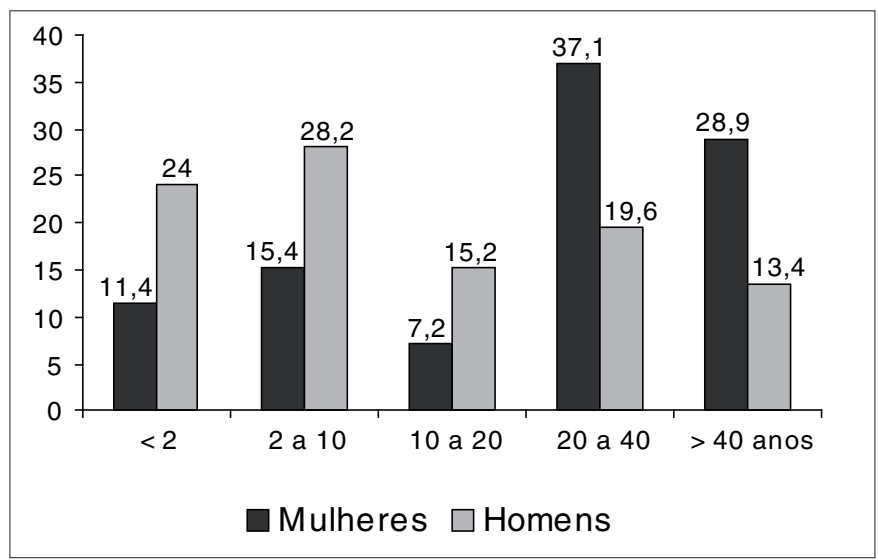

FIGURA 3. Percentual de diagnósticos por faixa etária entre homens $(\mathrm{n}=46)$ e mulheres $(\mathrm{n}=97)$. Fonte: ACELBRA-SC 2004

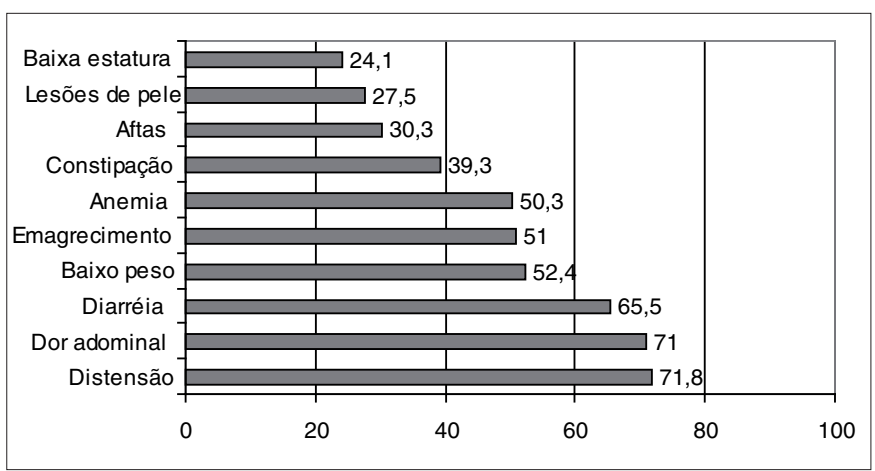

FIGURA 4. Freqüência de cada sintoma entre os membros da amostra $(\mathrm{n}=145)$. Fonte: ACELBRA-SC 2004 
Analisou-se também a freqüência dos sintomas entre os sexos (Figura 5), que revelou predomínio estatisticamente significante de sintomas considerados atípicos nas mulheres (aftas, constipação e anemia), enquanto nos homens predominaram os sintomas considerados típicos da doença (diarréia, baixo peso).

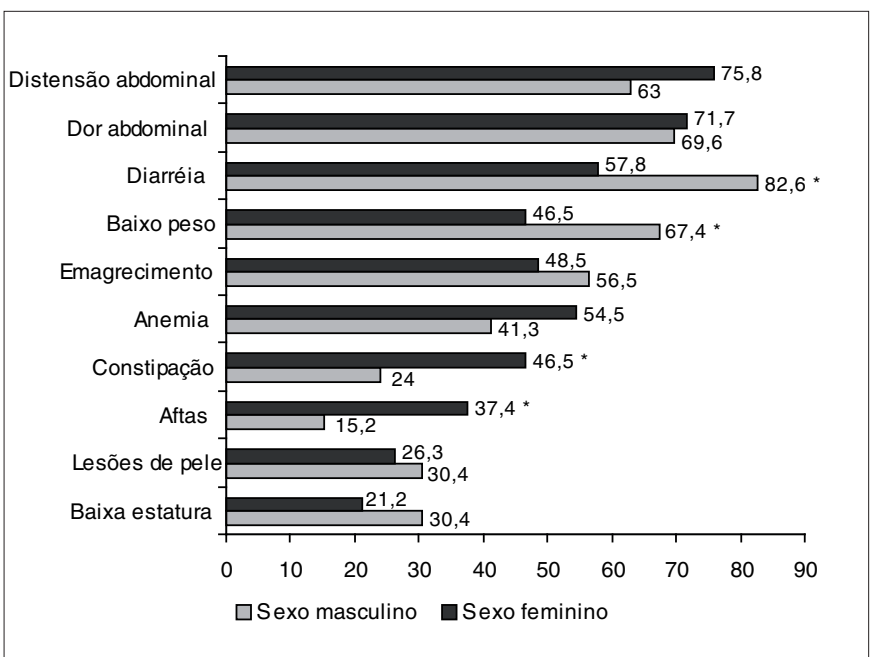

FIGURA 5. Percentual de cada sintoma entre as mulheres $(n=99)$ e os homens $(\mathrm{n}=46)$. Fonte: ACELBRA-SC 2004

${ }^{*} P<0,05$

$\mathrm{O}$ número de sintomas entre os participantes variou de 0 a 10 , com média de 4,8 (DP $=2,24)$. Essa média não diferiu significantemente entre os sexos, tendo sido de 4,86 (DP $=2,30)$ para os homens e de 4,81 (DP $=2,24)$ para as mulheres.

Quanto à investigação diagnóstica, como já dito, foram incluídos apenas os membros que realizaram biopsia de intestino delgado. Nesse grupo, o número de biopsias realizadas variou entre um e oito. Trinta e três por cento relataram terem sido submetidos a biopsia apenas em vigência de dieta contendo glúten, $42 \%$ apenas em dieta isenta de glúten, e 8,3\% tanto em dieta contendo glúten, quanto após sua retirada. Aproximadamente $12 \%$ participantes relataram terem sido submetidos a biopsia, porém não informaram sobre a vigência ou não de dieta contendo glúten na época em que foram biopsiados.

Com relação aos testes sorológicos, $61,4 \%$ dos participantes relataram terem sido submetidos a pelo menos um teste e, desses, 71\% relataram pelo menos um resultado alterado. Do total de participantes, apenas $44 \%$ possuíam pelo menos um teste sorológico alterado.

Foram submetidos a dosagem de anticorpos anti-gliadina do tipo IgA, 56,5\% dos participantes. Cinco por cento afirmaram não ter realizado o exame e 38,5\% não souberam informar. Dos que afirmaram terem feito o exame $(n=82), 32 \%$ relataram resultado normal, $67 \%$ resultado alterado e uma pessoa não soube informar o resultado.

Quanto à dosagem sérica de anticorpos anti-gliadina do tipo IgG, 52,4\% $(\mathrm{n}=76)$ dos participantes afirmaram terem sido submetidos ao exame. Desses, 29\% relataram resultado normal e $71 \%$ resultado alterado.
Trinta e quatro por cento dos participantes $(n=50)$ afirmaram ter realizado dosagem sérica de anticorpos anti-endomísio. Desses, $28 \%$ obtiveram resultado normal e $72 \%$ alterado.

Apenas 15 pacientes da amostra $(10,4 \%)$ foram submetidos a dosagem de anticorpos anti-transglutaminase. Desses, 86,7\% relatam resultado alterado e 13,3 não souberam informá-lo.

Após o diagnóstico, 45\% dos participantes afirmaram ter recebido indicação de suplementação vitamínica ou mineral. Percentagem semelhante $(45,5 \%)$ afirmou não ter recebido essa orientação e 9,5\% das pessoas não souberam informar. Quanto ao elemento (vitamina ou mineral) especificamente utilizado, $30 \%$ receberam indicação de suplementação de ferro, $14 \%$ de cálcio, $4,5 \%$ de zinco, $3,5 \%$ de cobre, $10,4 \%$ vitamina $D, 9,6 \%$ vitamina $\mathrm{B} 12$, e 10,4\% ácido fólico.

Com relação às doenças associadas e complicações relacionadas à doença celíaca, os participantes puderam assinalar mais de uma alternativa. No total, $65,5 \%$ dos participantes relataram possuir ao menos uma das entidades descritas. As freqüências de cada encontram-se descritas na Figura 6. Nenhum participante relatou possuir diabetes mellitus. Dos que haviam relatado lesões de pele como sintomas, apenas $50 \%$ assinalaram possuir dermatite herpetiforme como doença associada.

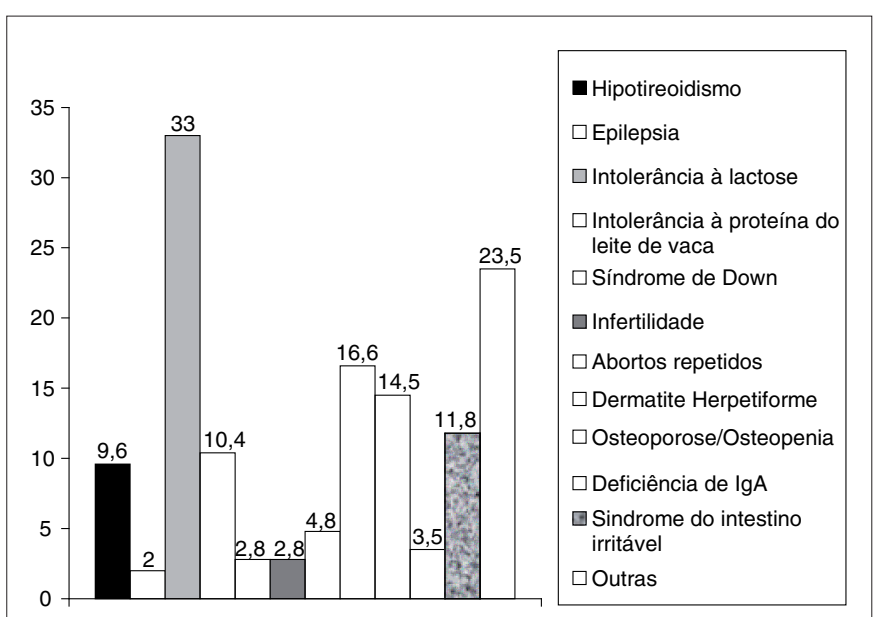

FIGURA 6. Percentual de participantes que relataram cada uma das doenças associadas $(n=145)$. Fonte: ACELBRA-SC 2004

Houve dois relatos de obstrução intestinal seguida de ressecção parcial do intestino delgado e um relato de linfoma gastrointestinal.

Quanto à realização de densitometria óssea, 35,2\% dos participantes afirmaram terem sido submetidos ao exame, $52,5 \%$ não foram submetidos e 12,3\% não souberam informar. Dos que o realizaram, 59\% relataram resultado alterado (osteopenia ou osteoporose), $40 \%$ resultado normal e 1\% não soube informá-lo.

\section{DISCUSSÃO}

Nos últimos anos, a doença celíaca tem sido cada vez mais reconhecida como entidade muito mais comum do que se pensava ${ }^{(7)}$ $\mathrm{O}$ aperfeiçoamento dos métodos de rastreamento - notadamente 
a detecção de anticorpos anti-endomísio, altamente sensíveis e específicos para a doença - permitiu a realização de inúmeros estudos populacionais, que culminaram por revelar taxas de doença celíaca - confirmada por biopsia - muito superiores às que se imaginava até então.

Apesar de diversos aspectos poderem sugerir o diagnóstico de doença celíaca, este somente poderá ser feito após a demonstração das alterações histopatológicas típicas em biopsia de intestino delgado durante uso de dieta contendo glúten ${ }^{(13)}$. Por esse motivo, optou-se por excluir desta análise os 16 indivíduos que não relatavam terem sido submetidos a biopsia para o diagnóstico. Estes corresponderam a aproximadamente $10 \%$ do total de participantes, número consideravelmente alto, ainda que inferior aos $25 \%$ observados em inquérito norte-americano ${ }^{(18)}$ e também inferior aos 14,5\% em estudo avaliando membros da ACELBRA - Seção São Paulo(43).

Ainda com relação ao papel da biopsia no diagnóstico da doença celíaca, é importante relembrar os critérios revisados em 1990 pela ESPGHAN ${ }^{(13)}$. De acordo com os mesmos, o diagnóstico de doença celíaca somente poderá ser feito nos indivíduos que possuírem história e apresentação clínica e testes sorológicos compatíveis, além de achados histopatológicos característicos em biopsia na vigência de dieta contendo glúten e exibirem melhora clínica e sorológica em resposta à dieta isenta do mesmo ${ }^{(2)}$. Outras causas de atrofia vilositária devem ter sido excluídas e o diagnóstico só deve ser feito em indivíduos com idade acima de $2 \operatorname{anos}^{(13)}$. Nos assintomáticos, a ESPGHAN preconiza a realização de nova biopsia após a isenção do glúten da dieta com o objetivo de comprovar a melhora dos padrões histopatológicos (recuperação da mucosa atrofiada e redução do infiltrado linfocitário intra-epitelial), para o diagnóstico definitivo ${ }^{(13)}$.

Com base nesses critérios, observou-se que apenas $42,1 \%$ dos associados analisados possuíam biopsias compatíveis com a investigação correta da doença. Destes, 33,8\% relatavam biopsias apenas durante dieta contendo glúten, o que seria compatível com o diagnóstico adequado, desde que os demais critérios de diagnóstico estivessem presentes, e 8,3\% possuíam duas ou mais biopsias, sendo pelo menos uma na vigência de glúten e uma na sua ausência - padrão considerado "ouro" para o diagnóstico.

Em contrapartida, 44,2\% dos participantes relataram terem sido submetidos a biopsia apenas durante dieta já isenta de glúten - padrão não compatível com o diagnóstico apropriado da doença. Diante deste fato, restam suposições: teriam esses indivíduos iniciado a dieta por conta própria antes do diagnóstico definitivo - ou seja, antes da realização da biopsia? Ou teriam sido orientados a proceder de tal forma por algum profissional de saúde? Ou responderam à questão acreditando que estivessem em dieta isenta de glúten e na realidade não estavam? São questões para as quais certamente não se encontrarão respostas no presente estudo, mas que servem de estímulo para trabalhos futuros e reforçam a necessidade de esclarecimento do público em geral e dos profissionais de saúde quanto ao correto diagnóstico desta doença.

Com relação à sintomatologia prévia ao diagnóstico, os sintomas "típicos" (ou da forma clássica de apresentação da doença) predominaram nesta série $65 \%$ dos membros relatando diarréia, $71 \%$ dor abdominal e 71,8\% distensão abdominal. Os resultados deste estudo são similares aos obtidos em dois outros brasileiros sobre o assunto ${ }^{(15,43)}$ e um norte-americano ${ }^{(18)}$, apesar de publicações recentes terem sugerido que as apresentações "atípicas" da doença seriam, na verdade, mais comuns que as "típicas"(37,49).

Achado que tem sido constante nos diversos estudos populacionais até hoje realizados é a alta prevalência da doença celíaca no sexo feminino em relação ao masculino. Em inquérito nacional norte-americano ${ }^{(18)}$, a razão de 2,9 mulheres para 1 homem foi encontrada, valor bastante semelhante ao de estudos populacionais europeus ${ }^{(21,46)}$ e que não difere muito dos encontrados na presente amostra (2,1:1 na amostra vs $1,8: 1$ na população total de membros da ACELBRA-SC). Na América Latina, poucos estudos de prevalência estão disponíveis. Estudo argentino revelou prevalência de 1:167 habitantes na região estudada, dos quais $67 \%$ eram mulheres e $33 \%$ homens $^{(19)}$. No Brasil, no primeiro estudo de prevalência realizado, diferenças de prevalência entre os sexos não puderam ser avaliadas, devido ao alto percentual de homens na amostra $-87,53 \%{ }^{(16)}$. Em posterior estudo de prevalência entre doadores de sangue, houve o cuidado de incluir número igual de participantes de ambos os sexos $(1500 \text { homens e } 1500 \text { mulheres })^{(31)}$. Desses, foram diagnosticados como celíacos 10 mulheres e 1 homem - proporção que, segundo os próprios autores, pode estar superestimada, uma vez que os 2 participantes que se recusaram a realizar a biopsia de intestino delgado eram homens ${ }^{(31)}$. Caso esses fossem, de fato, celíacos, essa proporção cairia para 3,3 mulheres para 1 homem - valor mais próximo mas, ainda assim, acima dos habituais $2: 1^{(31)}$. Já em estudo envolvendo membros da ACELBRA - Seção São Paulo, 62\% dos associados eram mulheres e 38\%, homens dados bastante semelhantes aos do presente estudo ${ }^{(43)}$. Por outro lado, no trabalho de prevalência brasileiro mais recentemente publicado, não houve diferença estatisticamente significativa de prevalência entre os $\operatorname{sexos}^{(35)}$, o mesmo tendo ocorrido na população pediátrica estudada por GALVÃO et al. ${ }^{(15)}$.

Apesar dos discordantes dados de prevalência nacionais, os valores desta série são compatíveis com grande parte da literatura internacional sobre o assunto, o que leva a concluir que a presente amostra pode ser considerada representativa dos celíacos do Estado, uma vez que segue o mesmo padrão de distribuição entre os sexos mundialmente descrito em estudos de grande porte. No mesmo sentido, se se considerar a prevalência de doença celíaca no Brasil de 1:681 (conforme descrito por GANDOLFI et al. ${ }^{(16)}$ ), verificar-se-á que a amostra presente corresponderia a 1,8\% do total de celíacos do Estado (de acordo com dados do Censo 2000 do IBGE, que aponta a população total em Santa Catarina de 5.356.360 habitantes). Esse valor é semelhante ao tamanho da amostra obtido por GREEN et al. ${ }^{(18)}$ em seu inquérito norte-americano, que correspondeu, na ocasião, a $2 \%$ do total de celíacos norte-americanos e foi considerada por esses autores como razoavelmente representativa da população celíaca daquele país.

À luz dos inúmeros estudos já citados ${ }^{(9,18,19,21,43,46)}$, que mostram maior prevalência e maior risco relativo de doença celíaca em mulheres do que em homens, seria de se esperar, também, maior 
índice de suspeita por parte dos médicos diante de mulheres com sintomas sugestivos, o que poderia levar a um diagnóstico mais precoce nas mesmas. Entretanto, no presente trabalho, o que se verificou foi exatamente o contrário - enquanto nos homens a média de idade ao diagnóstico foi de 16 anos, nas mulheres foi de 26,7, diferença estatisticamente significativa $(U=1487,5$; $\mathrm{Z}=3,21 ; P=0,0013)$. Diante desse achado, levantam-se as hipóteses de que, nesta amostra, ou as mulheres iniciaram com sintomas em idades mais avançadas, ou seu diagnóstico foi tardio, mesmo com os sintomas já presentes. Ainda, quando se comparam os percentuais de diagnóstico por sexo por faixa etária, percebe-se predomínio masculino nos diagnósticos feitos até os 20 anos de idade, padrão que se inverte após os mesmos, quando passam a predominar os diagnósticos em mulheres $\left(\chi^{2}=14,1948\right.$; graus de liberdade $=4$ e $\left.P=0,0067\right)$. Tal comportamento, no presente estudo, não pôde ser explicado por diferença quantitativa na sintomatologia apresentada entre homens e mulheres, tendo em vista que ambos apresentaram, em média, o mesmo número de sintomas (4,86 sintomas para os homens e 4,81 para as mulheres). Entretanto, talvez possa ser explicado por variações qualitativas na sintomatologia, haja vista que os homens apresentaram mais diarréia $(82,6 \%$ vs $57,8 \% ; P$ $<0,05)$, e déficit ponderal $(67,4 \%$ vs $46,5 \% ; P<0,05)$; enquanto as mulheres relataram mais constipação $(46,5 \%$ vs $24 \% ; P<0,05)$, aftas $(37,4 \%$ vs $15,2 \% ; P<0,05)$ e anemia $(54,5 \%$ vs $41,3 \% ; P$ $<0,05)$. Especula-se, dessa forma, se os sintomas apresentados pelos homens (diarréia e baixo peso) teriam sido mais preocupantes ou mais desagradáveis para os pacientes ou seus pais, do que aqueles apresentados pelas mulheres (constipação, anemia e aftas), de modo a levá-los à busca diagnóstica mais precoce. Outra possibilidade seria de que, realmente, as mulheres desta amostra apresentaram sintomas em idades mais avançadas (quando se sabe que tendem a predominar os sintomas atípicos), o que levaria a diagnóstico também numa faixa etária mais avançada nessa subpopulação.

Até o momento, poucos estudos foram publicados abordando especificamente a relação entre gênero e apresentação clínica da doença celíaca. O primeiro, publicado em $1995^{(9)}$, concluiu por uma apresentação mais sintomática, mais precoce e mais grave (maior número de complicações e de doenças associadas) nas mulheres, o que, entretanto, não explica os achados da presente série. Por outro lado, dois estudos mais recentes, ambos datados de 2005, chegaram a resultados que se aproximam mais daqueles observados nesta amostra. BARDELLA et al. ${ }^{(3)}$, estudando uma população italiana, encontraram diferenças estatisticamente significantes entre os sexos, apontando para a maior prevalência de diagnósticos em mulheres na faixa etária acima dos 14 anos, maior prevalência de anemia em mulheres, e maior prevalência de dor abdominal, dispepsia, vômitos e baixo peso em homens - todos achados concordantes com os deste estudo. Já em trabalho norte-americano ${ }^{(4)}$, não foram encontradas diferenças estatisticamente significantes entre os sexos quanto à idade ao diagnóstico ou à forma de apresentação da doença; entretanto, foram encontradas evidências indiretas de maior má absorção em homens (inferida por valores mais baixos de colesterol total e densidade mineral óssea), além de menor duração de sintomas antes do diagnóstico em homens - 33\% das mulheres contra 18\% dos homens possuíam história de mais de 5 anos de sintomas antes do diagnóstico $(P=0,006)$.

Quanto à tendência à agregação familiar da doença celíaca, estudo norte-americano ${ }^{(46)}$ revelou prevalência de $17,8 \%$ entre familiares em geral $\left(1^{\circ}\right.$ e $2^{\circ}$ grau $)$ de pacientes celíacos. $\mathrm{Na}$ ACELBRA-SC, $27 \%$ dos associados relataram a presença de familiares com doença celíaca - contra 19\% dos avaliados em inquérito nacional nos Estados Unidos ${ }^{(18)}$ e $6,2 \%$ dos celíacos da ACELBRA - Seção São Paulo ${ }^{(43)}$. Como se desconhece o número total de familiares dos associados, não se pode inferir a taxa de prevalência da doença entre esses. Entretanto, pode-se inferir que, caso não houvesse agregação familiar da doença, as taxas de prevalência nos familiares deveriam ser semelhantes à da população em geral, ou seja, de 1:681 ou $0,166 \%^{(16)}$ - valores bastante inferiores aos encontrados. Isso sugere existir, de fato, uma agregação familiar dos casos de doença celíaca, o que está de acordo com a teoria de que determinantes genéticos (especialmente os HLA DQ2 e DR4) estariam associados aos fatores ambientais (exposição às prolaminas) na gênese dessa doença $a^{(7)}$.

Quanto aos outros sintomas relatados pelos celíacos, além dos sintomas do aparelho gastrointestinal que não haviam sido incluídos nas alternativas anteriores (náuseas, vômitos, flatulência) e cuja alta freqüência já era esperada, tem destaque o grupo de sintomas neurológicos, psiquiátricos e comportamentais. Estes vêm sendo descritos cada vez mais freqüentes em associação à doença celíaca, embora a etiopatogenia dessa associação ainda não esteja completamente esclarecida ${ }^{(1,5)}$.

Com relação às condições associadas, destaca-se o elevado percentual de celíacos que afirmaram possuir no mínimo uma doença ou complicação relacionada à sua doença $(65,5 \%)$. Esse valor é consideravelmente superior aos 8,6\% encontrados em estudo semelhante realizado entre membros da ACELBRA - Seção São Paulo ${ }^{(43)}$; entretanto, vale ressaltar que, nessa última, $72 \%$ dos membros tinham idade igual ou menor que 20 anos, enquanto, na presente casuística, $62 \%$ eram maiores de 20 anos, tendo havido, portanto, maior tempo para o desenvolvimento de doenças associadas. Dessas, a mais freqüentemente relatada nesta casuística foi a intolerância à lactose (33\%). Entretanto, questiona-se o fato de ser essa a real prevalência dessa doença nessa população, levando-se em conta que, por terem sintomatologias semelhantes, um diagnóstico inicial de intolerância à lactose pode ter sido feito antes que o diagnóstico de doença celíaca fosse finalmente estabelecido. Pelo mesmo motivo, questiona-se também o alto percentual de doentes com intolerância à proteína do leite de vaca $(10,4 \%)$ e de síndrome do intestino irritável $(11,8 \%)$ que, em inquérito norte-americano, foi relatada por $36 \%$ dos celíacos como seu primeiro diagnóstico ${ }^{(18)}$. Quanto às demais doenças relatadas, acreditam-se serem mais confiáveis as informações, pois são diagnósticos bastante específicos e cuja apresentação geralmente não se confunde com a da doença celíaca ou outras. Destacam-se, ainda, os dois relatos de obstrução intestinal seguida de ressecção parcial do delgado, que devem, sem dúvida, levantar a hipótese de neoplasia maligna, bem como o relato específico de linfoma gastrointestinal em um associado 
- complicação maligna mais temida da doença celíaca e principal causa de morte entre os acometidos dessa afecção ${ }^{(11)}$.

Com relação à osteopenia e à osteoporose, reconhece-se hoje que o déficit de mineralização óssea e suas conseqüências são as complicações mais comuns da doença celíaca ${ }^{(28)}$. Estudo norteamericano mostrou que apenas $28 \%$ dos celíacos possuíam massa óssea normal à densitometria ${ }^{(32)}$. Na população aqui estudada, entretanto, apenas $14,5 \%$ relataram osteopenia ou osteoporose, o que possivelmente pode ser conseqüência do baixo percentual de participantes submetidos a densitometria óssea (apenas 35,2\% relataram tê-la realizado). Ressalta-se que, dentre os submetidos ao exame, quase $60 \%$ relataram massa óssea anormal, dado que está mais de acordo com a literatura mundial sobre o assunto ${ }^{(7)}$ e que sugere que a baixa prevalência encontrada na presente amostra deve-se, na realidade, ao baixo índice de investigação e diagnóstico dessas afecções.

\section{CONCLUSÕES}

No presente estudo, confirma-se a prevalência duas vezes maior de doença celíaca em mulheres, valor que está de acordo com a maior parte da literatura mundial, apesar de os estudos nacionais de prevalência terem obtido resultados conflitantes.

Foi, entretanto, achado totalmente inesperado o fato de as mulheres, nesta amostra, terem recebido o diagnóstico de doença celíaca em idades significativamente mais avançadas que os homens - dado que somente se repetiu na literatura em um estudo italiano ${ }^{(3)}$ e para o qual nem o presente estudo e nem o italiano possuem explicações. No mesmo sentido, foram também inesperadas as diferenças encontradas na sintomatologia entre homens e mulheres. A possibilidade de má absorção mais intensa nos homens, levantada por estudo norte-americano(4), pode explicar o fato de esses, na presente amostra, terem tido com maior freqüência diarréia e baixo peso. Infelizmente, dados como colesterol total e densidade mineral óssea, que foram utilizados no estudo norte-americano como evidências indiretas de maior má absorção, não foram especificamente investigados neste estudo. É interessante mencionar que muitas das diferenças sintomatológicas entre os sexos verificadas em nesta amostra foram também encontradas no estudo italiano anteriormente citado ${ }^{(3)}$, o que talvez possa seja explicado pelo fato de que, dentre as origens relatadas pelos participantes do presente estudo, a italiana foi a $2^{\mathrm{a}}$ mais apontada (quase $30 \%$ ), perdendo somente para a brasileira (43\%).

Surpreendeu ainda o número de associados que se consideravam celíacos e que, no entanto, não haviam sido submetidos a biopsia de intestino delgado para confirmação do diagnóstico ( $10 \%$ da amostra e 3\% do total de membros da ACELBRA-SC), bem como o número de participantes que relataram biopsias incompatíveis com uma investigação apropriada da doença $(44,2 \%$ foram submetidos a biopsia apenas após a exclusão do glúten da dieta). Esses dados indicam que ainda existe déficit de conhecimento tanto da população em geral quanto dos profissionais de saúde com relação à doença celíaca, o que pode estar gerando não só diagnósticos inapropriados em indivíduos saudáveis, condenandoos à dieta restritiva desnecessária, mas também impedindo que verdadeiros celíacos sejam diagnosticados.

Dessa forma, ressalta-se a importância das associações regionais de celíacos no sentido de esclarecimento tanto dos próprios celíacos e familiares, quanto da população em geral sobre a doença, e reforça-se a necessidade de ampla divulgação, entre médicos e demais profissionais de saúde, dos critérios para o correto diagnóstico dessa doença.

\section{AGRADECIMENTOS}

À direção do Centro de Ciências da Saúde da Universidade Federal de Santa Catarina, Florianópolis, SC, na pessoa do Prof. Dr. Carlos Alberto Justo e Silva, pela autorização do envio das cartas aos celíacos pelo malote postal dessa universidade. À UNICRED, pela doação de $\mathrm{R} \$ 404,80$ para a compra dos selos utilizados nas cartas-resposta. À Sra. Odete Maluf Teixeira, diretora ACELBRA-SC à época da realização da pesquisa, pelo apoio irrestrito à realização desse projeto.

Cassol CA, De Pellegrin CP, Wahys MLC, Pires MMS, Nassar SM. Clinical profile of Santa Catarina members of Brazilian Celiac Association. Arq Gastroenterol. 2007;44(3):257-65.

ABSTRACT - Background - Celiac disease is an enteropathy induced by gluten in genetically predisposed individuals. Aim - To establish the demographic and clinical characteristics of this disease in Santa Catarina State, Brazil. Methods - A descriptive transversal study was performed involving members of a regional celiac association, to whom a questionnaire focusing various aspects of the disease was sent. Results - From a total of 506 members, 145 (28.7\%) were enrolled in the study - all of them biopsy-proven celiacs. Their mean age was 30.8 years (range, 3.3-82.5 years). Female to male rate was 2.1:1. The mean age at diagnosis was 16 years for men and 26.7 years for women. Most frequently reported symptoms were: abdominal distention (71.8\%), abdominal pain (71\%) and diarrhea $(65.5 \%)$. Anemia, aphthous ulcers and constipation were more related by women, while diarrhea and low weight were more frequent in men. Only $42.1 \%$ of the participants had been submitted to biopsies compatible with a correct investigation of the disease ( $44.2 \%$ had been submitted to biopsy only after gluten exclusion of the diet and $11.7 \%$ did not mentioned whether they were in a gluten-free diet when biopsied). Only $61.4 \%$ had been submitted to serological tests for diagnostic or dietary control purposes. Associated diseases were related by $65 \%$ of the individuals, of which the most common was lactose intolerance (33\%). Vitaminic or mineral supplementation was indicated to $45 \%$ and only $32.5 \%$ have had bone mineral density measured. Of these, $59 \%$ had altered results. Conclusions - The results suggest a tendency of diagnosis of celiac disease in older ages, specially among women. This may indicate the necessity of improving public and medical knowledge in Santa Catarina concerning the diagnosis and treatment of this disease.

HEADINGS - Celiac disease. Peer group. Questionnaires. 


\section{REFERÊNCIAS}

1. Accomando S, Fragapane ML, Montaperto D, Trizzino A, Amato GM, Calderone F, Accomando I. Celiac disease and depression: two related entities? Dig Liver Dis. 2005;37:298-9

2. Bai D, Brar P, Holleran S, Ramakrishnan R, Green PH. Effect of gender on the manifestations of celiac disease: evidence for greater malabsorption in men. Scand J Gastroenterol. 2005;40:183-7.

3. Bardella MT, Fredella C, Saladino V, Trovato C, Cesana BM, Quatrini M, Prampolini L. Gluten intolerance: gender- and age-related differences in symptoms. Scand J Gastroenterol. 2005;40:15-9.

4. Book L, Zone JJ, Neuhausen SL. Prevalence of celiac disease among relatives of sib pairs with celiac disease in U.S. families. Am J Gastroenterol. 2003;98:377-81.

5. Carta MG, Hardoy MC, Boi MF, Mariotti S, Carpiniello B, Usai P. Association between panic disorder, major depressive disorder and celiac disease: a possible role of thyroid autoimmunity. J Psychosom Res. 2002;53:789-93.

6. Cellier C, Delabesse E, Helmer C, Patey N, Matuchansky C, Macintyre BJ, Cerf-Bensussan N, Brousse N, French Coeliac Disease Study Group. Refractory sprue, coeliac disease, and enteropathy-associated T-cell lymphoma. Lancet. 2000;356:203-8

7. Cerf-Bensussan N, Cellier C, Heyman M, Brousse N, Schmitz J. Coeliac disease: an update on facts and questions based on the 10th International Symposium on Coeliac Disease. J Pediatr Gastroenterol Nutr. 2003;37:412-21.

8. Chorzelski TP, Sulej J, Tchorzewska H, Jablonska S, Beutner EH, Kumar V. IgA clas endomysium antibodies in dermatitis herpetiformis and coeliac disease. Ann N Y Acad Sci. 1983;420:325-34

9. Ciacci C, Cirillo M, Sollazzo R, Savino G, Sabbatini F, Mazzacca G. Gender and clinical presentation in adult celiac disease. Scand J Gastroenterol. 1995;30:1077-81.

10. Ciclitira PJ, Moodie SJ. Transition of care between paediatric and adult gastroenterology. coeliac disease. Best Pract Res Clin Gastroenterol. 2003;17:181-95.

11. Corrao G, Corazza GR, Bagnardi V, Brusco G, Ciacci C, Cottone M, Sategna Guidetti CS, Usai P, Cesari P, Pelli MA, Loperfido S, Volta U, Calabro A, Certo M, Club del Tenue Study Group. Mortality in patients with coeliac disease and their relatives: a cohort study. Lancet. 2001;358:356-61.

12. Cronin CC, Shanahan F. Exploring the iceberg - the spectrum of celiac disease. Am J Gastroenterol. 2003;98:518-9.

13. Farrell RJ, Kelly CP. Diagnosis of celiac sprue. Am J Gastroenterol. 2001;96:3237-46.

14. Freeman H, Lemoyne M, Pare P. Coeliac disease. Best Pract Res Clin Gastroenterol. 2002; $16: 37-49$.

15. Galvão LC, Brandão JM, Fernandes MI, Campos AD. Apresentação clínica de doença celíaca em crianças durante dois períodos, em serviço universitário especializado. Arq Gastroenterol. 2004;41:234-8.

16. Gandolfi L, Pratesi R, Cordoba JC, Tauil PL, Gasparin M, Catassi C. Prevalence of celiac disease among blood donors in Brazil. Am J Gastroenterol. 2000;95:689-92.

17. Gasbarrini A, Torre ES, Trivellini C, De Carolis S, Caruso A, Gasbarrini G. Recurrent spontaneous abortion and intrauterine fetal growth retardation as symptoms of coeliac disease. Lancet. 2000;356:399-400.

18. Green PH, Stavropoulos SN, Panagi SG, Goldstein SL, McMahon DJ, Absan H, Neugut AI. Characteristics of adult celiac disease in the USA: results of a national survey. Am J Gastroenterol. 2001;96:126-31.

19. Gomez JC, Selvaggio GS, Viola M, Pizarro B, la Motta G, de Barrio S, Castelletto R, Echeverría R, Sugai E, Vazquez H, Mauriño E, Bai JC. Prevalence of celiac disease in Argentina: screening of an adult population in the La Plata area. Am J Gastroenterol. 2001;96:2700-4.

20. Howard MR, Turnbull AJ, Morley P, Hollier P, Webb R, Clarke A. A prospective study of the prevalence of undiagnosed coeliac disease in laboratory defined iron and folate deficiency. J Clin Pathol 2002;55:754-7.

21. Ivarsson A, Persson LA, Nystrom L, Hernell O. The Swedish celiac disease epidemic with a prevailing twofold higher risk in girls compared to boys may reflect gender specific risk factors. Eur J Epidemiol. 2003;18:677-84.

22. James SP. Immunologic, gastroenterologic, and hepatobiliary disorders. J Allergy Clin Immunol. 2003;111(2 suppl):s645-s58.

23. Kemppainen T, Kröger H, Janatuinen E, Arnala I, Kosma VM, Pikkarainen P, Julkunen R, Jurvelin J, Alhava E, Uusitupa M. Osteoporosis in adult patients with celiac disease. Bone. 1999;24:249-55.

24. Kennedy NP, Feighery C. Clinical features of coeliac disease today. Biomed Pharmacother. 2000;54:373-80.

25. King AL, Ciclitira PJ. Celiac disease: strongly heritable, oligogenic, but genetically complex. Mol Genet Metab. 2000;71:70-5.
26. Kumar V, Jarzabek-Chorzelska M, Sulej J, Rajadhyaksha M, Jablonska S. Tissue transglutaminase and endomysial antibodies — diagnostic markers of gluten-sensitive enteropathy in dermatitis herpetiformis. Clin Immunol. 2001;98:378-82.

27. Lahat E, Broide E, Leshem M, Evans S, Scapa E. Prevalence of celiac antibodies in children with neurologic disorders. Pediatr Neurol. 2000;22:393-6.

28. Lepers S, Couignoux S, Colombel JF, Dubucquoi S. La maladie coeliaque de l'adulte: aspects nouveaux. Rev Med Interne. 2004;25:22-34.

29. Mäki M, Collin P. Coeliac disease. Lancet. 1997;349:1755-9.

30. Martin-Villa JM, Lopez-Suarez JC, Perez-Blas M, Martínez-Laso J, Ferre-Lopez S, Garcia-Torre C, Lledó G, Manzanares J, Arnaiz-Villena A. Coeliac and enteropathyassociated autoantibodies in Spanish insulin-dependent diabetes mellitus patients and their relation to HLA antigens. J Diabetes Complications. 2001;15:38-43.

31. Melo SB, Fernandes MI, Peres LC, Troncon LE, Galvao LC. Prevalence and demographic characteristics of celiac disease among blood donors in Ribeirao Preto, Sao Paulo State, Brazil. Dig Dis Sci. 2006;51:1020-5

32. Meyer D, Stavropolous S, Diamond B, Shane E, Green PH. Osteoporosis in a north American adult population with celiac disease. Am J Gastroenterol. 2001;96:112-9.

33. Mowat AM. Coeliac disease - a meeting point for genetics, immunology, and protein chemistry. Lancet. 2003;361:1290-2

34. Oberhuber G. Histopathology of celiac disease. Biomed Pharmacother. 2000;54:368-72

35. Oliveira RP, Sdepanian VL, Barreto JA, Cortez AJ, Carvalho FO, Bordin JO, de Camargo Soares MA, da Silva Patrício FR, Kawakami E, de Morais MB, FagundesNeto U. High prevalence of celiac disease in Brazilian blood donor volunteers based on screening by IgA antitissue transglutaminase antibody. Eur J Gastroenterol Hepatol. 2007;19:43-9.

36. Peters U, Askling J, Gridley G, Ekbom A, Linet, M. Causes of death in patients with celiac disease in a population-based Swedish cohort. Arch Intern Med. 2003;163:1566-72.

37. Rampertab SD, Pooran N, Brar P, Singh P, Green PHR. Trends in presentation of celiac disease. Am J Med. 2006;119:355.e9-14.

38. Ransford RA, Hayes M, Palmer M, Hall MJ. A controlled, prospective screening study of celiac disease presenting as iron deficiency anemia. J Clin Gastroenterol. 2002;35:228-33.

39. Rostami K, Steegers EA, Wong WY, Braat DD, Steegers-Theunissen RP. Coeliac disease and reproductive disorders: a neglected association. Eur J Obstet Gyneco Reprod Biol. 2001;96:146-9.

40. Sategna-Guidetti C, Volta U, Ciacci C, Usai P, Carlino A, De Franceschi L, Camera A, Pelli A, Brossa C. Prevalence of thyroid disorders in untreated adult celiac disease patients and effect of gluten withdrawal: An Italian multicenter study. Am J Gastroenterol. 2001;96:751-7.

41. Sdepanian VL, de Morais MB, Fagundes-Neto U. Doença celíaca: a evolução dos conhecimentos desde sua centenária descrição original até os dias atuais. Arq Gastroenterol. 1999;36:244-57.

42. Sdepanian VL, de Morais MB, Fagundes-Neto U. Doença celíaca: avaliação da obediência à dieta isenta de glúten e do conhecimento da doença pelos pacientes cadastrados na Associação dos Celíacos do Brasil (ACELBRA). Arq Gastroenterol 2001;38:232-9

43. Sdepanian VL, de Morais MB, Fagundes-Neto U. Doença celíaca: características clínicas e métodos utilizados no diagnóstico de pacientes cadastrados na Associação dos Celíacos do Brasil. J Pediatr (Rio de J) 2001;77:131-8.

44. Sedghizadeh PP, Shuler CF, Allen CM, Beck M, Kalmar JR. Celiac disease and recurrent aphthous stomatitis: a report and review of the literature. Oral Surg Oral Med Oral Pathol Oral Radiol Endosc. 2002;94:474-8.

45. Vazquez H, Mazure R, Gonzalez D, Flores D, Pedreira S, Niveloni S, Smecuol E, Mauriño E, Bai JC. Risk of fractures in celiac disease patients: a cross-sectional, case-control study. Am J Gastroenterol. 2000;95:183-9.

46. Volta U, Bellentani S, Bianchi FB, Brandi G, De Franceschi L, Miglioli L, Granito A Balli F, Tiribelli C. High prevalence of celiac disease in Italian general population. Dig Dis Sci. 2001;46:1500-5.

47. Walker-Smith J, Murch S. Coeliac disease. In: Walker-Smith J, Murch S, editors Diseases of the small intestine in childhood. 4th ed. Oxford: Isis Medical Media;1999. p.235-77.

48. Zachor DA, Mroczek-Musulman E, Brown P. Prevalence of celiac disease in Down syndrome in the United States. J Pediatr Gastroenterol Nutr. 2000;31:275-9.

49. Zipser RD, Patel S, Baisch DW, Monarch E. "Atypical presentations" of celiac disease (CD) are the most common presentations. Am J Gastroenterol. 2001;96:113-4 